\title{
O TERCEIRO SETOR REGULAMENTADO: PRÁTICAS ADMINISTRATIVAS DE CIDADANIA E EFICIÊNCIA CONSTITUCIONAL APLICADA
}

\section{THE REGULATED THIRD SECTOR: ADMINISTRATIVE PRACTICES OF CITIZENSHIP AND CONSTITUTIONAL EFFICIENCY APPLIED}

\author{
Mateus Moura de Oliveira ${ }^{1}$ \\ José Gomes de Britto Neto ${ }^{2}$
}

\section{RESUMO}

Partindo de um estudo acerca da evolução dos modelos organizacionais de Estado, este trabalho almeja, a princípio, traçar a evolução destes no Estado Brasileiro, analisando o surgimento do Terceiro Setor como expoente do Estado Gerencial. Constata-se, posteriormente, o desenvolvimento das entidades da sociedade civil e a identificação da necessidade de regulamentação em face da disseminação de diversas espécies administrativas. Após breve relato das recentes práticas regulatórias desenvolvidas, conclui-se pela importância do Setor enquanto ápice do papel ativo da cidadania, ao passo que se defende a eficiência constitucional na atuação destas.

Palavras-chave: Terceiro Setor. Regulamentação. Eficiência Constitucional. Estado Gerencial. Sociedade Civil.

\begin{abstract}
Beginning from an approach about the evolution of organizational models of the States, this work goals, initially, outline the evolution of these models in the Brazilian State, analyzing the development of the Third Sector as an exponent of the Managing State. Establish afterwards the development of the entities of civil society and the urge for its regulation due to dissemination of its many species. After short report of the most recent regulatory practices, the importance of the Sector concludes itself as apex of the active role of citizenship, whereas advocate the constitutional efficiency in the atuation of such entities.
\end{abstract}

Keywords: Third Sector. Regulation. Constitutional Efficiency.Managing State. Civil Society.

\footnotetext{
${ }^{1}$ Mestrando em Direito Público pela Universidade Federal de Sergipe - UFS, Sergipe (Brasil). E-mail: matmouraadv@gmail.com

${ }^{2}$ Doutorando em Direito Público pela Universidade Federal da Bahia - UFBA, Sergipe, (Brasil). Mestre em Direito Econômico e Socioambiental pela PUC/PR. Especialista em Direito Tributário pela UCAM/RJ.

E-mail: jgbnadv@gmail.com
} 


\section{INTRODUÇÃO}

A prática atual dos Estados modernos ocidentais, no tocante à descentralização de atividades nos variados ramos estatais, vem sendo o de fiscalização, regulamentação e fomento de entidades privadas que atuam em áreas de interesse público. A delegação de tais funções auxilia os Estados em uma atuação mais efetiva e concreta nos mais diversos setores, ao passo em que possibilita uma maior concentração e eficiência das atividades remanescentes (GRAU, 2012).

No Brasil,este processo de descentralização surgiu a partir da década de 1990, seguindo uma tendência mundial pós-guerra de reestruturação e transformação do então Estado do Bem-Estar Social (Wellfare State) em um novo entitulado Estado Gerencial.

Este modelo organizacional em nosso país iniciou-se a partir de uma política de privatizações, diligenciando ao ramo privado o exercício e controle de atividades públicas tais quais energia e telecomunicações. Neste ínterim, para fins de efetiva organização das novas atividades delegadas ao setor privado, surgiram os primeiros mecanismos de controle, a partir de leis e órgãos regulamentadores (PEREIRA, 2006).

Dentro deste contexto de delegação e gerenciamento de atividades públicas, surgem também no Brasil entidades específicas, de caráter social, natureza privada, sem fins lucrativos, exercendo atividades de interesse público e social. O que a doutrina entitulou entidades do Terceiro Setor (REZENDE, 2000).

Estas, por sua vez, ao passo que foi reconhecido sua relevância na sociedade civil, passaram a ser fomentadas pelo Poder Público para exercer suas atividades, mediante certos requisitos e obrigação de prestar contas.

Contudo, inobstante seu crescente papel social, as entidades de Terceiro Setor passaram, durante a primeira década após sua criação, à míngua de instrumentos regulatórios bem estabelecidos, submetendo-se a regras por demais generalizadas e que não abarcavam a totalidade de suas espécies (SALOMÃO FILHO, 2008).

Tal lacuna deu-se em contraposição à crescente evolução e importância que as entidades assumiam junto a toda a sociedade, sendo então consideradas como o maior elo entre a atuação do Estado e a atuação privada, no exercício da plena cidadania em busca do bem comum.

Apenas nos últimos anos, com o advento de estudos prolongados do Poder Executivo e Legislativo com demais órgãos consultivos da sociedade civil, estabeleceram-se as 
primeiras diretrizes para normas regulamentadoras de caráter mais específico e restrito, na busca de uma maior eficiência destas entidades.

O presente trabalho se predispõe a demonstrar essa atuação regulamentadora frente à eficiência que se buscou alcançar. Em primeiro, identificar os modelos organizacionais de Estado que prevaleceram no Brasil nas últimas décadas, a fim de identificar a evolução para o surgimento do Terceiro Setor no estado em que se encontra. Em sequência, dispor sobre os principais estudos e desenvolvimento de práticas regulatórias para as organizações da sociedade civil nos últimos anos, delineando os principais pontos inovadores.Por fim, apontar as relevâncias de atuação das entidades do Terceiro Setor junto à sociedade civil, demonstrando assim práticas ativas de cidadania de extrema relevância para o desenvolvimento social comum, bem como a demonstração do princípio constitucional da eficiência como corolário destas novas práticas regulamentadoras.

Para o desenvolvimento da pesquisa foi utilizada pesquisa bibliográfica, buscando-se ainda embasamento teórico em artigos de revistas especializadas e dissertações de mestrado sobre o tema. Dividiu-se o presente trabalho em três eixos temáticos, onde o primeiro trata do surgimento e evolução do Estado liberal ao Estado regulador. O segundo eixo buscou demonstrar as novar regulamentações do terceiro setor no Direito Brasileiro. Por fim, tratouse de analisar as novas práticas regulatórias e as suas implicações no alcance da cidadania.

\section{DO ESTADO LIBERAL AO ESTADO REGULADOR: DO SURGIMENTO À REGULAMENTAÇÃO DO TERCEIRO SETOR}

O Estado Liberal, reconhecido historicamente como marco inicial para o surgimento do Direito Administrativo enquanto ramo especial do Direito, surgiu a partir da concepção de ideais liberais e revolucionárias que basearam a Revolução Francesa de 1789, a qual consagrou uma nova relação entre Estado e a sociedade (SARLET, 2011).

A Revolução trouxe com si o conceito de Estado de Direito, ou seja, o abandono do estado totalitário e absolutista, sendo este agora sujeito à lei e limitado pela mesma, de modo a também consagrar direitos fundamentais do homem não oponíveis ao Estado 3 .

\footnotetext{
${ }^{3}$ Neste ponto, Ivo Dantas destaca que "O liberalismo, em uma visão total, deve ser identificado, igualmente, em duas perspectivas - econômica e política - as quais se fundem a fim de moldar o que se costuma denominar
} 
Esta concepção, presente na denominada primeira dimensão de direitos fundamentais, preconizava a defesa dos direitos civis e políticos, em que a Administração Pública assumia uma competência negativa para com a sociedade. Isto é, o nãointervencionismo nas relações privadas sociais e econômicas, assumindo um papel passivo e tão somente garantidor do exercício de tais direitos.

Sobre tal momento histórico:

O Estado, naquele momento, seria considerado um inimigo do povo, o que era compreensível pelas arbitrariedades cometidas durante a época do Absolutismo. Apenas naquelas situações em que fosse fundamental o poder de autoridade estatal (poder de império), seria o Estado habilitado a intervir nas relações privadas, geralmente através de atos impositivos (atos administrativos), para se garantir a propriedade e a liberdade dos indivíduos (direitos fundamentais de primeira geração) (OLIVEIRA, 2015)

O Estado Liberal perpetuou-se a partir do século XVIII até início do século XX, refletindo-se nas Constituições francesa (1791) e brasileira (1824). Essa nova Ordem econômica implicou em uma conformação jurídica para tender somente o respeito aos direitos fundamentais, a exemplo da liberdade e propriedade, assegurando a todos, nos limites da lei, o acesso a tais direitos. Época marcada pelo Estado mínimo ou negativo. Nessa fase, o direito privado sempre será o meio mais adequado para a manifestação da vontade privada, principalmente na ordem jurídica onde lhe é conferida caráter conformador da ordem jurídica econômica. Nessa ótica, o direito privado constitui um limite intransponível a atividade de intervenção econômica do Estado, apesar do fato de que os destinatários dessa intervenção serem, cada vez mais, entidades privadas, cuja ação se pretende associar à do Estado em prol dos objetivos desse (MONCADA, 2003).

A partir de então, tomou lugar um novo cenário, o qual exigiu um diferente papel do Estado nas relações entre o mesmo e os particulares(SAMPAIO, 2013).Contudo, a nãointervenção estatal e o abstencionismo de práticas regulatórias acabou por acarretar numa desigualdade social caracterizada por monopólios e descontrole de mercado, deteriorando as características do Estado Liberal, e culminando na crise de 1929. A Administração Pública, até então meramente de competências negativas, passou a ser vista como uma aliada a atuar positivamente na ordem econômica e social (PEREIRA, 2000).

Estado Liberal.”. In: DANTAS, Ivo. Instituições de Direito Constitucional Brasileiro. $2^{\text {a }}$ ed. Curitiba: Juruá, 2003, p.102. 
As causas de transição da escola liberal para a social se reportam a uma série de fatores, dentre eles, questões de ordem política e social. Esse modelo jurídico trouxe como fundamento a funcionalização crescente da autonomia privada à vontade dos poderes públicos bem como o papel positivo da norma jurídica na conformação da vida econômica e social. Houve, com isso, um esvaziamento da distinção entre o público e o privado. Esses não correspondem mais a domínios distintos. A ideia é que o simples jogo das vontades e interesses privados não tem condições de dirimir, por vezes, conflitos de ordem social e econômica, às vezes irredutíveis. Assim, o direito aparece para conformar o exercício da atividade privada em razão de interesses que assume em nome dos princípios da solidariedade social e outros.

Assim, a nova ordem jurídica, calcada na Constituição Mexicana de 1917 e de Weimar de 1919, busca o reequilíbrio da liberdade e da igualdade que foram suprimidos com as mudanças ocorridas, conformando a ordem econômica à ordem social.

Após o período da Primeira e Segunda Guerras Mundiais, surge o Estado Social de Direito (Welfare State), com a intervenção estatal social e econômica, de modo a regular e balizar excessos, com o intuito de proteção a direitos fundamentais eminentemente coletivos. Os serviços públicos foram vastamente ampliados, e a "mão do Estado" fez-se valer nos mais diversos ramos considerados de interesse público.

O então recente Estado do Bem-Estar Social passou, em face da grande concentração de atividades no poder estatal, a descentralizar atividades em sua estrutura, de modo a melhor gerenciar os diversos ramos abarcados.

Todavia, a grande concentração de serviços no Poder Público trouxe, em sentido reverso ao que se almejava, a uma ineficiência das atividades administrativas. A hipertrofia do aparato estatal, a burocratização e má qualidade dos serviços públicos prestados, o déficit econômico e fiscal, foram fatores que buscaram uma redifinição da intervenção estatal ora preconizada (SARLET, 2011).

Sobre este ponto:

\footnotetext{
A necessidade de desburocratização da Administração Pública, com o intuito de agilizar a atuação estatal e torná-la eficiente, acarreta o 'retorno do pêndulo', ou seja, o Estado devolve aos particulares diversas tarefas, especialmente as de caráter econômico (diversas empresas públicas e sociedades de economia mista demonstraram-se ineficientes), e entrega, inclusive, tarefas que até então eram exclusivamente desempenhadas pelo poder público (privatiazção de serviços públicos). (OLIVEIRA, 2015)
} 
Reformula-se o conceito de "atividades imprescindíveis" do Estado. Redefine-se áreas de atuação e meios de alcançar os objetivos almejados. Prioriza-se o resultado, transfere-se atividades-a priori públicas- ao setor privado. Neste contexto, a partir da década de 1980, a chamada onda de privatizações atinge diversos países, como Estados Unidos, GrãBretanha, Austrália e Nova Zelândia, os quais também passaram por ajustes fiscais (PEREIRA, 1998).

No Brasil, a década de 1990 consagrou esta tendência, através de instrumentos como o Programa Nacional de Desestatização (PND), as Emendas Constitucionais $\mathrm{n}^{\circ} 5,8$ e 9 de 1995, e a Emenda Constitucional $n^{\circ}$ 19/98, que trouxe o princípio da eficiência ao rol dos princípios norteadores da Administração Pública em nossa Carta Magna, culminando na conceituação de uma "Administração Pública Gerencial" e na busca de um "Estado Mínimo".

Sobre este novo conceito:

O embasamento do Estado mínimo consiste na ideia de enxugamento das atividades estatais, com o fito de tornar este mesmo Estado mais ágil, mais eficiente e mais provedor das atividades que assim se fazem imprescindíveis para a manutenção da sociedade como um todo. (DUR ÃO, 2015)

Neste ínterim, o Estado Regulador desponta como nova maneira de gerir o interesse público, delegando a particulares a participação na elaboração de determinadas políticas e serviços. Acerca das novas características do Estado Regulador:

\footnotetext{
É importante esclarecer que a diminuição do aparelho estatal e a reformulação das atividades que devem ser desenvolvidas pelo Estado não significam um simples retorno ao Estado Liberal clássico, pois, agora, o Estado não abdica da intervenção na área econômica e social. A mudança primordial está justamente na técnica utilizada para essa intervenção, que deixa de ser direta e passa a ser indireta (subsidiariedade), notadamente através da regulação (Estado Regulador) e do fomento público.(CARVALHO, 2015)
}

Pode-se dizer que a concretização do Estado Regulador no ordenamento brasileiro teve como um de seus pontos fortes a criação das agências reguladoras, idealizadas inicialmente pelo Plano Nacional de Desestatização e consolidadas no início da década de 2000, com a finalidade de fiscalizar e regulamentar as práticas públicas delegadas a particulares. (CARVALHO, 2015)

Em paralelo, também surgem no ordenamento brasileiro as chamadas entidades do Terceiro Setor:

[...] entidades da sociedade civil de natureza privada, sem fins lucrativos, que exercem atividades de interesse social e coletivo e que, por este motivo, recebem 
incentivos do Estado, que exerce, em relação a elas, uma atividade de fomento. (JUNIOR, 2007)

As entidades de Terceiro Setor, assumiram, no âmbito do Estado Regulador, importante papel no exercício de atividades de interesse social, sendo criadas diversas espécies, como as Organizações Sociais (Lei 9.637/98), as Organizações da Sociedade Civil de Interesse Público (Lei 9.790/99), Organizações Não-Governamentais (ONGs), Serviços Sociais Autônomos, entre outros.

A participação destas entidades na Administração Pública evoluiu de um papel assistencial para uma efetiva e crucial função que o Estado não conseguia abarcar. A própria sociedade, ao enfrentar situações desfavoráveis em seu âmbito, mobiliza-se para melhorar aquele cenário. E o Estado, reconhecendo nisto sua importância, fomenta e incentiva estas mobilizações (MELLO, 2011).

Sobre tal evolução:

Assim, só recentemente começou-se a reconhecer a importância desse setor no âmbito da sociedade e da economia contemporâneas pela sua capacidade de mobilização de recursos humanos e materiais para o atendimento de importantes demandas sociais que, frequentemente, o Estado não tem condições de atender; pela sua capacidade de geração de empregos (principalmente nas sociedades mais desenvolvidas, onde os investimentos sociais são bem maiores); e pelo aspecto qualitativo, caracterizado pelo idealismo de suas atividades - enquanto participação democrática, exercício de cidadania e responsabilidade social. (PAES, 2013)

Diversos setores de grande importância acabam por se beneficiar desta atuação social fomentada. O Estado, há muito não mais visto como absoluto e detentor de tudo, reconhecidamente carece de suporte nas áreas em que não pode (ou consegue) alcançar (MEIRELLES, 2009).

Basta ver, por exemplo, diversas ações sociais de apoio a idosos, suporte a órfãos, entre tantos outros, que saem da própria esfera social em que se encontram. A sociedade passa a ser também polo ativo nas ações de interesse público.

E justamente por reconhecer tal importância, estas entidades, que recebem fomento do Estado, precisariam ser devidamente regularizadas, cumprindo requisitos essenciais para seu pleno funcionamento, de modo a ser cada vez mais eficiente o fomento repassado pelo Poder Público. 


\section{NOVAS REGULAMENTAÇÕES DO TERCEIRO SETOR BRASILEIRO: O DIÁLOGO ENTRE ESTADO E ORGANIZAÇÕES DA SOCIEDADE CIVIL}

O pós-positivismo do final do século XX defende em suas bases não só uma validade formal das leis, mas uma validade material. A validação da norma pressupõe seu reflexo ético e social, e a interpretação da mesma em face do caso concreto. (LENZA, 2009)

Por viés análogo, o movimento neoconstitucionalista traz uma posição destacada e central à Constituição como base do ordenamento, concedendo aos cidadãos direitos subjetivos a serem exigidos perante o Estado (SILVA, 2010). Não se tratam mais de meras normas programáticas, mas disposições vinculantes a todos os Poderes. Sobre o movimento:

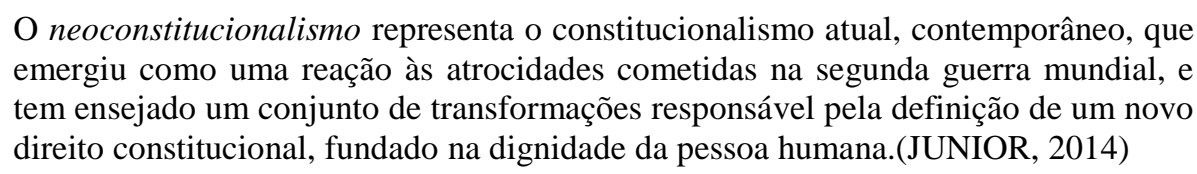

Em união a estes movimentos, o Direito Administrativo também evolui, trazendo como instrumento de validade e legitimidade de seus atos o diálogo social ${ }^{4}$. A supremacia do interesse público sobre o privado passa por uma releitura, e a Administração Dialógica toma lugar como instrumento de validação de atos administrativos, como convênios, concessões, contratos, entre outros.

O surgimento e ideia da dialogia administrativa no Direito passa pela legitimação do próprio Estado. Partindo-se, por exemplo, da noção de Peter Häberle de que a Constituição é um processo público de diálogo e conflito de noções indeterminadas, as ações do Poder Público devem fazer parte deste diálogo, agindo em conjunto com tantos outros agentes sociais para interpretação de normas e efetivação constitucional (BRANCO,2010).

Assim, há que se falar numa constante e saudável discussão para que os atos administrativos não só sejam válidos, mas plenamente eficazes. Eficácia esta que, desde o final da década de 90, passou a ser foco dos atos públicos com a Emenda Constitucional 19/98 (LIMA, 2007).

\footnotetext{
${ }^{4}$ Neste ponto, Rafael de Carvalho reforça que "[...]a atividade impositiva perde espaço para atuação consensual da Administração[...]em vez da imposição unilateral da vontade estatal por meio do ato administrativo.". Forense: Rio de Janeiro, 2015, p. 33.
} 
A eficiência, da mesma maneira, torna-se princípio norteador para os atos da Administração.Sobre tal princípio, conceitua-se:

[...]significa, como resulta das lições de Guido Falzone, em desenvolver a atividade administrativa do modo mais congruente, mais oportuno e mais adequado aos fins a serem alcançados, graças à escolha dos meios e da ocasião de utilizá-los, concebíveis como os mais idôneos para tanto. (MELLO, 2011)

Ainda:

O núcleo do princípio é a procura da produtividade e economicidade e, o que é mais importante, a exigência de reduzir os desperdícios do dinheiro público, o que impõe a execução dos serviços públicos com presteza, perfeição e rendimento funcional. (FILHO, 2007)

Ou seja, não mais é suficiente um ato público total e formalmente constituído. Tampouco é suficiente que os procedimentos sejam os corretos. Aliado a tudo isto, devem ser eficientes de maneira prática, prevenindo o mal uso da máquina pública (DI PIETRO, 2010).

Em face disto, além da já proclamada aproximação entre sociedade e Estado na execução de funções públicas, concerna-se sobre a real eficiência de tais relações e a regulação dos diversos contratos celebrados (MEDAUAR E OLIVEIRA, 2006).

O hibridismo entre o direito público e privado é realidade inegável nos atuais contratos e parcerias celebrados pela Administração. A regulação destas relações, já presente em alguns setores, faz-se igualmente crucial no Terceiro Setor brasileiro.

Em 2008, o Estado brasileiro, em resposta à crise imobiliária dos Estados Unidos, e em comunhão com suas políticas governamentais da época, buscou uma atuação mais incisiva do Estado Regulador nas relações com entidades privadas (BONAVIDES, 2010).

O sucesso de entidades do terceiro setor na realização das funções públicas, embora majoritário, não era então constante. As práticas regulatórias aplicadas até o momento não abrangiam todo um leque de entidades existentes, que como dito, passavam à míngua de regulação e efetiva fiscalização.

Em contraponto, o Terceiro Setor a esta época já era realidade em diversos países e ordenamentos. Segundo dados da OECD (Organisation for Economic Co-operation and Development), cerca de $80 \%$ dos serviços do Reino Unido passam por contratação externa e atuação de entidades privadas, ao lado de $65 \%$ nos Estados Unidos, 50 a $60 \%$ na Noruega, Suécia, Suíca, Nova Zelândia e Austrália (GRAU, 2012).

Porém, não se está pondo aqui uma visão totalmente pessimista do quadro de regulamentações das organizações da sociedade civil. Em verdade, muitas espécies haviam sido regualmentadas ainda no final da década de 90. 
A lei das Organizações Sociais (9.637/98) foi um bom demonstrativo de regulamentação que vingou até os dias atuais, sofrendo mínimas alterações necessárias com o tempo. Os Serviços Sociais Autônomos, embora não regularizados diretamente, foram direcionados para atividades específicas que até hoje justificam a atuação de suas entidades no desenvolvimento e aperfeiçoamento de indivíduos, como é o caso do SENAE, SEBRAE, SESC e outros.

Contudo, como já dito outrora, as OS, OSCIP, e os Serviços Sociais Autônomos são apenas exemplos de uma gama de entidades de terceiro setor. A estas últimas, restam práticas regulatórias não somente para sua real fiscalização, mas principalmente para sua melhor eficiência (CAPEZ, 2008).

Logo, precisava-se de medidas que abarcassem uma maior abrangência setorial.

A fim de combater estas lacunas, constituiu-se em 2011 um Grupo de Trabalho Interministerial (GTI) pela Secretaria-Geral da Presidência da República com o foco de diagnosticar e propor soluções às relações jurídicas entre entidades do terceiro setor e o Poder Público (LOPES E VICHI, 2015).

Sobre este grupo:

\begin{abstract}
O Grupo de Trabalho Interministerial (GTI), encarregado do diagnóstico e proposição de soluções aos entraves jurídicos e institucionais relacionados ao universo das organizações e as suas parcerias com o poder público, e que atuou de novembro de 2011 a julho de 2012, coordenado pela SG/PR, contou com a participação da Casa Civil da Presidência da República; da Controladoria-Geral da União (CGU); da Advocacia-Geral da União (AGU); do Ministério do Planejamento, Orçamento e Gestão (MPOG); do Ministério da Justiça (MJ); do Ministério da Fazenda (MF); do Instituto de Pesquisa Econômica Aplicada(IPEA) e catorze organizações de representatividade nacional indicadas pela "Plataforma por um Novo Marco Regulatório para as Organizações da Sociedade Civil”. (SOUZA E FIGUEIREDO, 2015)
\end{abstract}

Um dos resultados deste grupo foi a elaboração e promulgação da Lei 13.019/2014, entitulada Marco Regulatório das Organizações da Sociedade Civil (MROSC), a qual trouxe novos e importantes requisitos para celebração de parcerias com entidades do Terceiro Setor, não só em relação às entidades mas também em relação à própria Administração (LOPES e VICHI, 2015).

Como exemplos disto, passa-se a exigir um procedimento licitatório específico para parceria com tais entidades, as quais devem cumprir uma série de requisitos exigidos em edital. A mesma, por sua vez, deve comprovar não só experiência nas atividades que propõe, como estrutura administrativa interna qualificada (OLIVEIRA, 2015). 
Também a fiscalização das entidades deixa de ser tão somente do Poder Público (Ministério Público e Tribunal de Contas) mas igualmente da sociedade, que passa a ter real direito de exigir prestações de contas e acompanhar de perto o cumprimento da parceria.

Esta lei, embora de aplicabilidade embrionária (visto que vigente apenas a partir de 23/01/2016, e apenas para entidades federais), trouxe consigo novas tendências regulatórias para o terceiro setor, consolidando a Administração Dialógica como forma de controle social e a eficiência como princípio constitucional norteador das práticas administrativas do setor (PAES, 2013).

Tendências estas que, ressalve-se, ainda encontram-se em desenvolvimento. Vários grupos de estudo tiveram continuação nestes temas e também o Congresso Nacional, sugerindo alterações no decurso entre a promulgação e validade do Marco Regulatório.

Surgiu assim a Medida Provisória 684/2015, posteriormente transformada na Lei 13.204/2015, a qual alterou substancialmente a Lei 13.019/2014, e, diga-se, não se espera ser a última modificação.

Em decorrência das grandes mudanças, uma das alterações foi justamente o adiamento da vacatio legis com relação a Estados e Municípios, passando a ver o Marco Regulatório apenas a partir de 2017. Também, determinadas exigências junto ao corpo administrativo e gerencial das entidades de Terceiro Setor foram alteradas, concentrando algumas atividades em determinadas figuras.

Ao mesmo tempo, expandiu a quantidade de organizações a serem abrangidas, como organizações religiosas de cunho social, sociedades cooperativas, entre outras, e diferenciou parcerias da Administração que não envolvam transferência de recursos financeiros (o chamado acordo de cooperação).

Não obstante, não cabe a este presente trabalho discorrer sobre todas as transformações do Marco, visto ser este, embora de extrema relevância, apenas um instrumento no universo de discussões teóricas e práticas sobre a regulamentação do Terceiro Setor.

Conforme dito anteriormente, a elaboração deste importante Marco Regulatório foi apenas um dos resultados de um entre vários grupos de discussão surgidos.

As deliberações sobre as entidades da sociedade civil foram múltiplas e multifacetadas. Não só por parte do poder público, mas por iniciativa destas próprias entidades, que desejavam da mesma maneira uma forma mais eficiente não só de atuar como de criar elos reais com a Administração. 
À parte de resultados efetivos ou não, que por decerto só poderão ser observados com o tempo, deve-se ressaltar a importante dialogia que ocorreu entre setor público e privado na busca de soluções. Dialógo este que abre portas para práticas futuras.

\section{NOVAS PRÁticas REGULATÓRIAS DO TERCEIRO SETOR: PRÁTICA DE CIDADANIA E A BUSCA DA EFICIÊNCIA CONSTITUCIONAL}

O exercício dos direitos políticos e sociais estabelecidos em uma Constituição é um dos conceitos mais simples porém eficazes de cidadania. Cidadania esta que pode se realizar de diversas formas, indiretas ou diretas, na busca de um bem comum.

Com a evolução da sociedade em que vivemos, quebra-se o conceito de que o cidadão é sujeito passivo apenas legitimador das ações estatais, e de que o Estado é o único obrigado a preservar o interesse público e social. A própria sociedade é parte ativa neste cenário.

A partir da evolução apontada no primeiro tópico deste trabalho, pode-se compreender melhor os motivos que levaram à tomada de ações pelas entidades privadas e que culminaram no fomento do Poder Público. O reconhecimento de que uma sociedade multifacetada jamais poderia ser plenamente atendida por via única foi uma evolução do gerenciamento estatal, crucial para o presente status quo.

Em contrapartida, a autorização de uso do erário por entidades privadas poderia resultar na malversação das finanças públicas se não controlado. Ao mesmo tempo, se a ênfase é justamente alcançar o interesse público da maneira mais plena possível, a administração e aplicação de recursos também deveria ser fiscalizada.

No Brasil, um dos primeiros padrões desta política estatal deu-se nos anos $2000 \mathrm{com}$ o surgimento das agências reguladoras, criadas para fiscalizar e regulamentar ações de entidades privadas em áreas de interesse público, como telecomunicações, energia, aviação, entre outras.

Partindo deste raciocínio para o Terceiro Setor, a existência de lacunas fiscalizatórias obviamente chamou a atenção da sociedade, principalmente quando do surgimento dos primeiros casos de mal uso do dinheiro público, seja por má administração ou desvio de finalidade destas entidades, tendo como maior amostra escândalos nacionais com ONGs utilizadas por parlamentares corruptos. 
Entrementes, não se pode julgar boas práticas por seus maus exemplos. De fato, a atuação efetiva de entidades da sociedade civil em determinados ramos auxiliou a Administração na efetivação de políticas públicas que anteriormente tinham diversas dificuldades quanto a sua aplicabilidade.

Tome-se como amostra o caso de uma determinada comunidade que apresenta alto número de jovens ligados ao consumo de drogas ilícitas. $\mathrm{O}$ alto número de viciados, por sua vez, aumenta a criminalidade local, diminui a renda, e consequentemente, as condições habitacionais.

Antes mesmo da intervenção estatal neste contexto, os próprios membros desta comunidade, identificando tais problemas, criam serviços de conscientização local, concessão de abrigos aos jovens já marginalizados, abertura de centros de reabilitação, entre outras medidas.

E isto tudo através de uma abordagem local, ciente de todas as dificuldades e obstáculos daquele lugar. Cria-se assim uma aproximação do problema muito superior a qualquer política geral que porventura a Administração Pública assumisse.

Reconhecendo a efetividade destas ações, o Poder Público não só incentiva como fomenta estas atividades, pois a existência deste grupo social é interessante não só para aquela comunidade como para o interesse público como um todo.

Nesta toada, também a sociedade percebe, através dos resultados alcançados, que é peça-chave neste cenário, e que as práticas cidadãs são de crucial importância para o desenvolvimento de uma comunidade. Não só a nível local, como foi este exemplo, mas regional e até mesmo nacional.

Nada mais correto assim que afirmar, como outrora já dito, que as práticas do Terceiro Setor da Administração Pública são o maior exemplo de cidadania popular ativa em nossa sociedade, porquanto feita de forma conjunta e organizada. Também através de princípios dialógicos com a Administração, esta cidadania é reforçada através de um discurso real sobre a efetividade de novas medidas a serem tomadas.

Mas não para por aí. Se por um lado tais práticas favorecem uma maior eficiência social, a eficiência financeira tampouco pode ser descartada.

Afinal, a atuação do Poder Público não consiste apenas em permissão, mas também fomento. E se há fomento, há dinheiro público que está sendo direcionado àquele serviço, que por sua vez deve demonstrar máxima efetividade nas finanças. 
A princípio, observou-se que as regulamentações iniciais não tiveram sucesso, tanto por não abrangerem todas as espécies de entidades da sociedade civil, como também tratavam-se de meras imposições a serem cumpridas pelas entidades, com enfoque financeiro.

A partir de então, o estudo das novas práticas regulatórias passou a ter novo enfoque: a eficiência constitucional, elencada a princípio fundamental da Administração Pública pela EC 19/98, refletida não só no setor financeiro mas de maneira global. A concessão de meios para que as entidades da sociedade civil não só soubessem administrar suas finanças, e sim sua própria máquina administrativa local. Uma verdadeira reforma do modelo de administração pública, voltado para a gestão gerencial.

O princípio da eficiência, igualado então aos princípios da legalidade, impessoalidade, moralidade e publicidade, foi justamente inserido no caput do art. 37 como demonstrativo de sua importância perante os demais atos administrativos. A chamada Reforma Gerencial concretizou medidas para a modernização da máquina pública até então apenas engatinhadas em projetos de lei esparsos.

E com o desenvolver deste modelo gerencial, o Estado de certo modo relativizou sua supremacia perante o interesse privado, assumindo para este fim um posicionamento mais horizontal (embora não total) de direitos e deveres para com setor privado, respeitadas certas peculiariedades .

O Marco Regulatório aqui discutido foi bom exemplo de lei regulatória que prevê não só obrigações do Terceiro Setor como da Administração. Criação de conselhos consultivos, de gestão e de prestação de contas são exemplos simples entre os vários desenvolvidos no intuito de constituir um auxílio mútuo entre Estado e sociedade.

Ainda dentro do Marco Regulatório, novas disposições foram criadas para aperfeiçoar leis regulatórias do final da década de 90, como é o caso da Lei das OSCIP (9.790/1999) e a própria Lei de Improbidade Administrativa (8.429/92). Tudo isto para trazer maior eficácia às disposições normativas preexistentes.

Assim, o desenvolvimento de novos grupos de estudo para criação de práticas regulatórias e fiscalizadoras tende a criar medidas eficientes para o acompanhamento e evolução do Terceiro Setor, nos moldes já atendidos anteriormente, visando perspectivas futuras. 


\section{CONCLUSÕES}

As novas práticas oriundas de uma nova atuação do Estado Gerencial em nosso ordenamento culminaram no panorama atual do terceiro setor brasileiro, caracterizado principalmente por entidades com atuação próxima aos reais problemas sociais, auxiliando sobremaneira o Poder Público em ações de grande interesse público.

Tais ações das organizações da sociedade civil, conforme já frisado, trouxeram à tona o importante papel do terceiro setor na Administração Pública enquanto expoente da cidadania atuante.

Neste contexto, observou-se a necessidade de uma regulamentação do setor à medida de sua gradual evolução, resultando assim em grupos de estudo criados no início da década, de modo a buscar soluções legislativas para regulamentação das organizações da sociedade civil.

A primeira destas soluções foi a promulgação da lei 13.019/2014, conhecida por Marco Regulatório das Organizações da Sociedade Civil (MROSC), que trouxe consigo a tentativa de melhorar as relações entre Estado e Terceiro Setor, através de suporte à administração das entidades, respeito a impessoalidade na convocação para celebração de parcerias, e avanços na prestação de contas das OSCs para com o Estado, no intuito de evitar malversamento ou mau uso de dinheiro público destinado às mesmas.

O desenvolvimento de práticas regulatórias nesta linha evidencia-se como um importante incentivo para práticas de cidadania ativa, reforçando o papel da sociedade atuante na busca do bem-estar social. Contudo, mais que um incentivo, o caminho da regulação no

terceiro setor deve também buscar a eficiência, a fim de não só "fazer", mas de "melhor fazer".

Isto é, cuidar para que as finalidades precípuas das entidades da sociedade civil sejam não só alcançadas, como alcançadas da maneira mais eficaz possível, administrativa e financeiramente.

Inobstante estarmos diante de primeiros passos neste sentido, faz-se mister o prosseguimento e evolução destas práticas, de modo a construir um melhor controle e regulação em setor tão importante no desenvolvimento do interesse público. 


\section{REFERÊNCIAS}

BOBBIO, Norberto. A Era dos Direitos. Nova edição. Rio de Janeiro: Elsevier, 2004.

BRANCO, Paulo Gustavo Gonet; COELHO, Inocêncio Mártires; MENDES, Gilmar Ferreira. Curso de Direito Constitucional. $5^{\text {a }}$ ed. São Paulo: Saraiva, 2010.

BRASIL. Instituto Brasileiro de Geografia e Estatística. As Fundações Privadas e Associações sem fins lucrativos no Brasil. Gerência do Cadastro Central de Empresas. Rio de Janeiro: IBGE, 2012.

Ministério do Planejamento. Relações de Parceria entre Poder Público e Entes de Cooperação e Colaboração no Brasil. Secretaria de Gestão. Brasília, Ministério do Planejamento, 2010.

BONAVIDES, Paulo. Curso de Direito Constitucional. 25ª ed. São Paulo: Malheiros, 2010.

CAPEZ, Fernando; CHIMENTI, Ricardo Cunha; SANTOS, Marisa Ferreira dos; ROSA, Márcio Fernando Elias. Curso de Direito Constitucional. 5ª ed. São Paulo: Saraiva, 2008.

CARVALHO, Kilbare Gonçalves. Direito Constitucional: Teoria do Estado e da Constituição. Direito Constitucional Positivo. 17ª ed. Belo Horizonte: Del Rey, 2011.

CARVALHO, Matheus. Manual de Direito Administrativo. $2^{\text {a }}$ ed. Salvador: Juspodivm, 2015.

DANTAS, Ivo. Instituições de Direito Constitucional Brasileiro. $2^{\text {a }}$ ed. Curitiba: Juruá, 2003.

DI PIETRO, Maria Sylvia Zanella. Direito Administrativo. 23ª ed. São Paulo: Atlas, 2010.

FERRAREZI, Elisabete. OSCIP - Organização da sociedade civil de interesse público: a lei 9.079/99 como alternativa para o terceiro setor. Brasília: Comunidade Solidária, 2000.

FILHO, José dos Santos Carvalho. Manual de Direito Administrativo. 17 a ed. Rio de Janeiro: Lumen Juris, 2007. 
FILHO, Marçal Justen. Curso de Direito Administrativo. 8ª ed. Belo Horizonte: Fórum, 2012.

GRAU, NuriaCunill. Qué há pasado com lo público em los últimos 30 años? Balance y perspectivas. Revista de la CLAD Reforma y Democracia, Caracas, n. 52, fev. 2012. Disponível em: <http://old.clad.org/portal/publicaciones-del-clad/revista-clad-reformademocracia/articulos/052-febrero-2012/Cunill.pdf> Acesso em 02 dez 2015.

NAP, 1998.

Repensando o público através da sociedade. Rio de Janeiro. Revan: Brasília, DF:

IOSCHPE, Evelyn (org.). $3^{o}$ Setor: desenvolvimento social sustentado. Rio de Janeiro: Paz e Terra, 2005.

JUNIOR, Dirley da Cunha. Curso de Direito Constitucional. $8^{\text {a }}$ ed. Salvador: Juspodivm, 2014.

Curso de Direito Administrativo. 6ª ed. Salvador: Juspodivm, 2007.

LENZA, Pedro. Direito Constitucional Esquematizado. 13ª ed. São Paulo: Saraiva, 2009.

LIMA, Ruy Cirne. Princípios de Direito Administrativo. $7^{\mathrm{a}}$ ed. São Paulo: Malheiros, 2007.

LOPES, Laís de Figueiredo; VICHI, Bruno de Souza. A Lei 13.019/2014: Conquistas, Desafios e os Impactos para a gestão pública estadual e municipal. Congresso CONSAD de Gestão Pública, 2015, Brasília.

LOPEZ, Francisco e NIETO Y MALLO. La ordenacion legal de las fundaciones. Madrid: La Ley Temas, 2006.

LUNA, Cabra de GARCIA, Lorenzo. La constelación de las entidades no lucrativas: el tecer sector. In ob. Col. El Sector no lucrativo em España. Madrid, 1993.

MEDAUAR, Odete; OLIVEIRA, Gustavo Justino. Consórcios públicos: comentários a Lei 11.107/2005. São Paulo: RT, 2006. 
MEIRELLES, Hely Lopes. Direito Administrativo Brasileiro. $35^{\text {a }}$ ed. São Paulo: Malheiros, 2009.

MELLO, Celso Antônio Bandeira de. Curso de Direito Administrativo. $28^{\mathrm{a}}$ ed. São Paulo: Malheiros, 2011.

MELLO, Oswaldo Aranha Bandeira de. Princípios Gerais de Direito Administrativo. $2^{\circ}$ vol. Rio de Janeiro: Forense, 1969.

MORAES, Guilherme Peña de. Curso de Direito Constitucional. $2^{\mathrm{a}}$ ed. Rio de Janeiro: Impetus, 2008.

NOHARA, Irene Patrícia. Direito Administrativo. 5a ed. São Paulo: Atlas, 2008.

OLIVEIRA, Rafael Carvalho Rezende. Novo Perfil de Regulação Estatal: Administração Pública de Resultados e Análise de Impacto Regulatório. Rio de Janeiro: Forense, 2015.

. Administração Pública, Concessões e Terceiro Setor. $3^{\mathrm{a}}$ ed. Rio de Janeiro: Forense; São Paulo: Método, 2015.

ORMEROD, Alexandre Rodriguez Bueno. Administração Pública Dialógica e Legitimação da Atuação Administrativa. Rio de Janeiro: Escola de Magistratura do Estado do Rio de Janeiro, 2012. 26 f. Programa de Pós-Graduação. ESMERJ, 2012. Disponível em: <http://www.emerj.tjrj.jus.br/paginas/trabalhos_conclusao/1semestre2012/trabalhos_12012/al exandreormerod.pdf $>$ Acesso em 20 out 2015.

PAES, José Eduardo Sabo. Fundações, Associações e Entidades de Interesse Social: aspectos jurídicos, administrativos, contábeis, trabalhistas e tributários. $8^{\mathrm{a}}$ ed. Rio de Janeiro: Forense, 2013.

PEREIRA, Luiz Carlos Bresser; SPINK, Peter (orgs.). Reforma do Estado e Administração Pública Gerencial. 7ª ed. Rio de Janeiro: FGV, 2006.

PEREIRA, Luiz Carlos Bresser. Reforma do Estado para a Cidadania: A Reforma Gerencial Brasileira na Perspectiva Internacional. São Paulo: ed. 34, Brasília: ENAP, 1998. 
. A Reforma Gerencial do Estado de 1995. Revista de Administração Pública, Lisboa, jul 2000, vol 34, n. 4. Disponível em: <http: // www. bresserpereira.org.br/ papers/ 2000/81RefGerenc1995-INA.pdf> Acesso em $10 \mathrm{dez} 2015$.

REZENDE, Isan de Oliveira. Terceiro setor: a nova fronteira do terceiro milênio. Brasília: Instituto Yacaré, 2000.

SALOMÃO FILHO, Calixto. Regulação da atividade econômica (princípios e fundamentos jurídicos). $2^{\text {a }}$ ed. São Paulo: Malheiros, 2008.

SAMPAIO, José Adércio Leite. Teoria da Constituição e dos Direitos Fundamentais. Belo Horizonte: Del Rey, 2013.

SARLET, Ingo Wolfgang. A eficácia dos direitos fundamentais: uma teoria geral dos direitos fundamentais na perspectiva constitucional. $11^{\mathrm{a}}$ ed. Porto Alegre: Livraria do Advogado, 2011.

SILVA, José Afonso da. Curso de Direito Constitucional Positivo. 33ª ed. São Paulo: Malheiros, 2009.

TACHIZAWA, Takeshy. Organizações não governamentais e Terceiro Setor: criação de ONGs e estratégias de atuação. $3^{\mathrm{a}}$ ed. São Paulo: Atlas, 2007.

VITULLO, Gabriel Eduardo (org.). A ideologia do "Terceiro Setor": ensaios críticos. Natal: EDUFRN, 2012. 